\title{
The association of erythrocyte sedimentation rate, high-sensitivity C- reactive protein and diabetic kidney disease in patients with type 2 diabetes
}

Shizhe Guo ${ }^{1 \dagger}$, Meng Wang ${ }^{1 \dagger}$, Yifei Y $u^{1}$, Yeping Yang ${ }^{1}$, Fangfang Zeng ${ }^{1}$, Fei Sun ${ }^{1}$, Qin $\mathrm{Li}^{2}$, Min He${ }^{1}$, Yiming $\mathrm{Li}^{1}$, Jie Wen ${ }^{1,3}$, Wei Gong ${ }^{1 *}$ and Zhaoyun Zhang ${ }^{1 *}$

\begin{abstract}
Background: To evaluate the association between high-sensitivity C-reactive protein (hsCRP) and erythrocyte sedimentation rate (ESR), and diabetic kidney disease (DKD) in patients with type 2 diabetes mellitus (T2DM).

Methods: A cross-sectional study was conducted in 1210 patients with T2DM, among whom 265 had DKD. The severity of DKD was assessed by estimated-glomerular filtration rate (eGFR) and urinary albumin creatinine ratio (ACR). The relationship between ESR, hsCRP and DKD was analyzed by multivariate logistic analysis. The relationship between ESR and eGFR, ESR or ACR was analyzed by multivariate linear regression.

Results: ESR (23.0 [12.0 41.5] mm/h versus 12.0 [7.0 22.0] mm/h, $P<0.001)$ and hsCRP (3.60 [2.20 7.65] versus $2.90[1.80 \sim 5.60] \mathrm{mg} / \mathrm{L} \mathrm{mg} / \mathrm{L}, P<0.01)$ values were significantly higher in patients with DKD than those without. Patients with higher ESR or hsCRP had lower eGFR and higher ACR. After adjusted for gender, age, hemoglobin, plasma proteins, $\mathrm{HbA}_{1 \mathrm{c}}$, lipid profiles, and the usage of renin-angiotensin system inhibitors, ESR but not hsCRP was independently associated with the rate and severity of DKD in patients with T2DM.
\end{abstract}

Conclusion: ESR was independently associated with the rate and severity of DKD in patients with T2DM.

\section{Background}

Type 2 diabetic mellitus (T2DM) is a chronic metabolic disorder with multiple complications, including diabetic retinopathy, diabetic neuropathy, diabetic kidney disease (DKD) as well as cardiovascular diseases [1]. DKD affects $20-40 \%$ of patients with T2DM, and is the leading cause of end-stage renal disease (ESRD) [2]. With the rapidly growing prevalence of DKD, there is an overwhelming requirement for biomarkers which can predict the omset and severity of DKD.

\footnotetext{
*Correspondence: nj_gongwei2001@sina.cn; zhaoyunzhang@fudan.edu.cn 'Shizhe Guo and Meng Wang contributed equally to this work. 'Department of Endocrinology and Metabolism, Huashan Hospital, Fudan University, 12 Wulumuqi Road, Shanghai 200040, China

Full list of author information is available at the end of the article
}

T2DM is related to an exacerbated systematic inflammation [3]. Chronic inflammation in patients with T2DM is involved in the onset and development of DKD [4]. Mounting evidences have shown that a number of molecules related to inflammation can be predictable in DKD. Urinary tumor necrosis factor- $\alpha$ (TNF- $\alpha$ ), interleukin-8 (IL-8), and monocyte chemo-attractant protein-1 (MCP1) are found to be elevated in patients with DKD $[5,6]$. Gohda et al. found that circulating TNF receptors were strongly associated with renal function loss in patients with DKD [7]. On ground of this, circulating inflammatory markers might be relevant to the diagnosis and prognosis of DKD [8].

(c) The Author(s). 2020 Open Access This article is licensed under a Creative Commons Attribution 4.0 International License, which permits use, sharing, adaptation, distribution and reproduction in any medium or format, as long as you give appropriate credit to the original author(s) and the source, provide a link to the Creative Commons licence, and indicate if changes were made. The images or other third party material in this article are included in the article's Creative Commons licence, unless indicated otherwise in a credit line to the material. If material is not included in the article's Creative Commons licence and your intended use is not permitted by statutory regulation or exceeds the permitted use, you will need to obtain permission directly from the copyright holder. To view a copy of this licence, visit http://creativecommons.org/licenses/by/4.0/ The Creative Commons Public Domain Dedication waiver (http://creativecommons.org/publicdomain/zero/1.0/) applies to the data made available in this article, unless otherwise stated in a credit line to the data. 
Among all plasma inflammatory biomarkers, erythrocyte sedimentation rate (ESR) and high-sensitivity Creactive protein (hsCRP) are the mostly commonly used laboratory tests for identifying systematic inflammation [9]. Both ESR and hsCRP are important markers in various inflammation-related diseases. For example, ESR and hsCRP are higher in sarcoidosis patients or osteoarthritis compared to healthy controls [10, 11]. Latest report also revealed that elevated ESR and CRP were associated with the increased urinary albumin excretion [12]. However, there is no study exploring the relationship between ESR, hsCRP and the risk as well as the severity of DKD.

In this study, we retrospectively studied a cohort of 1210 patients with T2DM to investigate the potential relationship between DKD and the degree of systemic inflammation measured by ESR and hsCRP.

\section{Methods}

\section{Study design and participants}

From January 2013 to October 2017, patients with T2DM who were hospitalized in department of Endocrinology and Metabolism of local hospital were enrolled in this study. The study was approved by the ethics committee of Huashan Hospital (Approval No:2014-250). Written informed consent was obtained from all participants. The exclusion criteria were as follows: (1) patients with immune deficiency; (2) patients with a history of operation or acute coronary syndrome within a month; (3) patients with malignant tumors; (4) patients with a history of inflammatory conditions including current infection, rheumatoid arthritis, systemic lupus erythematosus, ankylosing spondylitis, live cirrhosis, tuberculosis, etc.; and (5) patients with the history of steroid usage. All participants included in our study had physical examination and medical history review.

\section{The criteria for diabetic kidney disease}

DKD was defined as patients with macro-albuminuria or patients with micro-albuminuria in the presence of diabetic retinopathy according to the diagnostic criteria from KDOQI clinical practice guidelines [13]. Macroalbuminuria was defined as an albumin creatinine ratio (ACR) $>300 \mathrm{mg} / \mathrm{g}$ and micro-albuminuria is defined as ACR between 30 and $300 \mathrm{mg} / \mathrm{g}$ in two of three urine sample collections [13].

\section{Laboratory parameters}

Demographic data (age, gender, status of hypertension) were collected from medical records. Hypertension was diagnosed if patients had history of hypertension or had blood pressure above $140 / 90 \mathrm{mmHg}$ for twice obtained on $\geq 2$ occasions [14]. Fasting blood sample was collected to measure fasting plasma glucose (FBG), glycated hemoglobin $\left(\mathrm{HbA}_{1 \mathrm{c}}\right)$, hsCRP, serum albumin (ALB), globulin (GLB), total cholesterol (TC), triglyceride (TG), high-density lipoprotein cholesterol (HDL) and lowdensity lipoprotein cholesterol (LDL), serum creatinine ( $\mathrm{SCr}$ ), and ESR. Besides, the record of renin-angiotensin system (RAS) inhibitors usage was also collected.

The level of $\mathrm{HbA}_{1 \mathrm{c}}$ was measured by liquid chromatography VARIANTTM II and D-10 Systems, BIORAD, USA). ESR was measured using ESR-30 fully automatic dynamic analyzer (Shanghai Xunda Medical Instrument Co., Ltd., China). FBG, TC, TG, HDL, LDL, ALB, total protein, $\mathrm{SCr}$ was quantified by Beckman AU5800 (Beckman Coulter Inc., Brea, CA). HsCRP was detected by iCHROMA reader (Boditech Med inc, Gangwon-do, Korea). Urine was collected for third times and then ACR was immediately measured using Turbidimetry Hitachi system (Roche, Mannheim, Germany). Estimated-glomerular filtration rate (eGFR) was calculated according to CKD-EPI formula (Male: $141 \mathrm{x}$ min $(\mathrm{SCr} / 0.9,1)-0.411 \times \max (\mathrm{SCr} / 0.9,1)-1.209 \times 0.993$ Age; Female: $141 \times \min (\mathrm{SCr} / 0.7,1)-0.329 \times \max (\mathrm{SCr} / 0.7,1)$ $-1.209 \times 0.993$ Age $\times 1.018)$ [13]

\section{Statistical analysis}

All analyses were performed by SPSS version 21.0 for windows system. Categorical variables were exhibited by frequencies and percentages, with $\mathrm{X}^{2}$ test or Fisher's exact test for detecting the difference. Continuous data was expressed as median values and 25th-75th percentiles because of non-normal distribution analyzed by Kolmogorov-Smirnov test. Kruskal-Wallis test and Mann-Whitney $U$ test were conducted to evaluate the difference. Multivariable linear regression analysis and logistic analysis were used to assess the relationship between inflammatory biomarkers and DKD. A two-tailed $P<0.05$ was defined as statistically significant.

\section{Results}

Basic characteristics

A total of 1210 patients with T2DM were included in the current analysis, of whom 265 had DKD. Comparison of the characteristics were listed in Table 1. Compared with patients without DKD, patients with DKD showed higher ESR value $(12.0$ [7.0 22.0] $\mathrm{mm} / \mathrm{h}$ vs 23.0 [12.0 41.5] $\mathrm{mm} / \mathrm{h}, P<0.001)$ and higher hsCR $P$ value $(2.90[1.80 \sim 5.60] \mathrm{mg} / \mathrm{L}$ vs $3.60[2.20 \sim 7.65] \mathrm{mg} / \mathrm{L}$, $P<0.01)$.

Besides, compared with patients without DKD, those with DKD has higher ACR (12.56 [7.04 27.38] mg/g vs $394.49[96.64 \sim 1316.90] \mathrm{mg} / \mathrm{g}, \quad P<0.001)$ and lower eGFR (92.04 [78.10 101.72] $\mathrm{ml} / \mathrm{min} / 1.73 \mathrm{~m}^{2}$ vs 75.69 [48.13 95.18] $\mathrm{ml} / \mathrm{min} / 1.73 \mathrm{~m}^{2}, \mathrm{P}<0.001$ ), as well as higher GLB, TC, TG, LDL and lower HDL, ALB levels (Table 1). The use of aspirin $(p=0.021)$ and metformin 
Table 1 Characteristics of patients with or without diabetic kidney disease

\begin{tabular}{|c|c|c|c|}
\hline Variables & $\begin{array}{l}\text { Patients without DKD } \\
(n=945)\end{array}$ & Patients with DKD $(n=265)$ & $P$ value \\
\hline Age (years) & $65.24(59.00 \sim 75.03)$ & $67.00(59.70 \sim 79.00)$ & 0.005 \\
\hline Female (n, \%) & $400(42.33 \%)$ & $110(41.51 \%)$ & 0.83 \\
\hline Smoking (n, \%) & $275(29.1 \%)$ & $76(28.7 \%)$ & 0.90 \\
\hline Duration of T2DM (years) & $9.80(5.35 \sim 14.25)$ & $9.10(5.50 \sim 14.20)$ & 0.71 \\
\hline BMI $\left(\mathrm{kg} / \mathrm{m}^{2}\right)$ & $25.00(22.25 \sim 27.85)$ & $24.9(21.90 \sim 28.10)$ & 0.74 \\
\hline Hypertension (\%) & $598(63.28 \%)$ & $221(83.40 \%)$ & $<0.001$ \\
\hline \multicolumn{4}{|l|}{ Medicine used (n, \%) } \\
\hline Metformin & $502(53.1 \%)$ & $107(40.4 \%)$ & $<0.001$ \\
\hline Thiazolidinediones & $35(3.7 \%)$ & $11(4.2 \%)$ & 0.74 \\
\hline Statins & $402(42.5 \%)$ & $123(46.4 \%)$ & 0.26 \\
\hline Aspirin & $236(25.0 \%)$ & 85 (32.1\%) & 0.021 \\
\hline RASi & $365(40.7 \%)$ & $151(57.0 \%)$ & $<0.001$ \\
\hline $\mathrm{ESR}(\mathrm{mm} / \mathrm{h})$ & $12.00(7.00 \sim 22.00)$ & $23.00(12.00 \sim 41.50)$ & $<0.001$ \\
\hline hsCRP (mg/L) & $2.90(1.80 \sim 5.60)$ & $3.60(2.20 \sim 7.65)$ & $<0.001$ \\
\hline WBC $\left(\times 10^{9} / L\right)$ & $6.43(5.35 \sim 7.76)$ & $6.66(5.60 \sim 8.01)$ & 0.039 \\
\hline NEU (\%) & $58.35(52.03 \sim 64.60)$ & $61.50(55.45 \sim 68.80)$ & $<0.001$ \\
\hline $\mathrm{Hb}(\mathrm{g} / \mathrm{L})$ & $134.00(123.00 \sim 146.00)$ & $127.00(114.00 \sim 136.50)$ & $<0.001$ \\
\hline$A L B(g / L)$ & $37.00(35.00 \sim 40.00)$ & $35.00(31.00 \sim 38.00)$ & $<0.001$ \\
\hline $\mathrm{GLB}(\mathrm{g} / \mathrm{L})$ & $27.00(24.00 \sim 30.00)$ & $28.00(25.00 \sim 31.00)$ & $<0.001$ \\
\hline $\mathrm{HbA}_{1} \mathrm{C}(\%)$ & $8.20(7.00 \sim 9.90)$ & $8.60(7.30 \sim 10.10)$ & 0.10 \\
\hline FBG $(\mathrm{mmol} / \mathrm{L})$ & $7.26(5.82 \sim 9.67)$ & $7.90(6.10 \sim 10.93)$ & 0.017 \\
\hline $\mathrm{TC}(\mathrm{mmol} / \mathrm{L})$ & $4.26(3.57 \sim 5.07)$ & $4.46(3.73 \sim 5.39)$ & 0.006 \\
\hline TG $(\mathrm{mmol} / \mathrm{L})$ & $1.33(0.92 \sim 1.97)$ & $1.52(1.01 \sim 2.22)$ & 0.002 \\
\hline $\mathrm{HDL}(\mathrm{mmol} / \mathrm{L})$ & $0.97(0.84 \sim 1.15)$ & $0.92(0.80 \sim 1.08)$ & $<0.001$ \\
\hline $\mathrm{LDL}(\mathrm{mmol} / \mathrm{L})$ & $2.38(1.82 \sim 3.03)$ & $2.60(1.83 \sim 3.29)$ & 0.005 \\
\hline ACR $(\mathrm{mg} / \mathrm{g})$ & $12.56(7.04 \sim 27.38)$ & 394.49 (96.64 1316.90) & $<0.001$ \\
\hline $\mathrm{SCr}(\mu \mathrm{mol} / \mathrm{L})$ & $67.84(56.00 \sim 79.93)$ & $84.00(64.50 \sim 108.40)$ & $<0.001$ \\
\hline $\operatorname{eGFR}\left(\mathrm{ml} / \mathrm{min} / 1.73 \mathrm{~m}^{2}\right)$ & $92.04(78.10 \sim 101.72)$ & 75.69 (48.13 95.18) & $<0.001$ \\
\hline
\end{tabular}

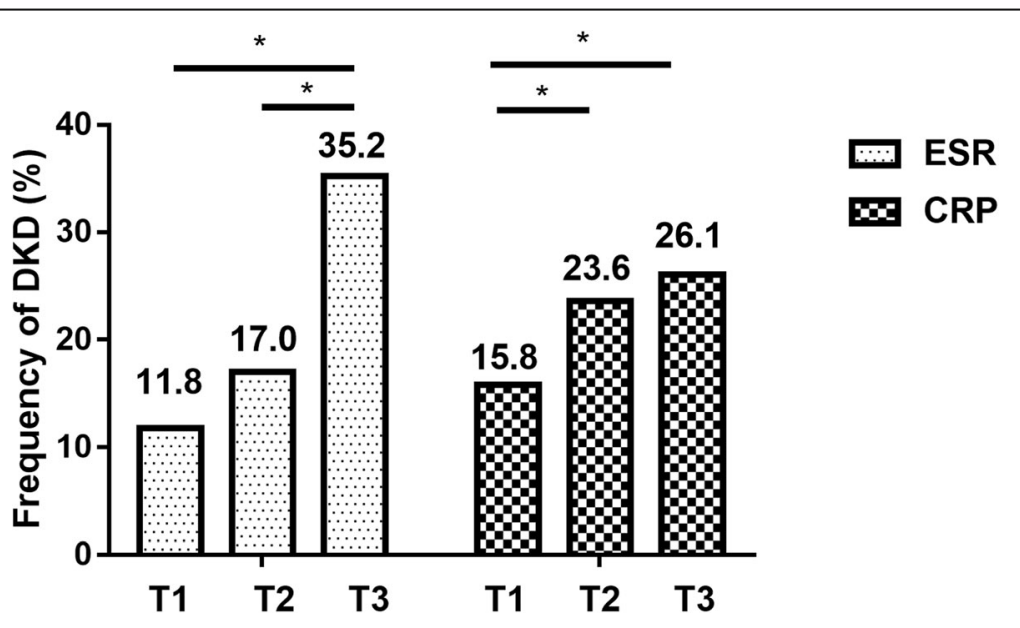

Fig. 1 Frequency of DKD in subgroups according to ESR and CRP tertiles. Legends: $: p<0.05$. ESR: erythrocyte sedimentation rate, CRP: $C$ reactive protein 
$(p<0.001)$ between two groups also reached statistical significance.

\section{Both ESR and hsCRP were associated with renal damage in T2DM}

Patients were then divided into three subgroups based on the tertiles of ESR (ESR-T1: $\leq 8 \mathrm{~mm} / \mathrm{h}$, ESR-T2: 8 $21 \mathrm{~mm} / \mathrm{h}$, and ESR-T3: $>21 \mathrm{~mm} / \mathrm{h})$. The occurrence of DKD rose in accompany with ESR elevation (Fig. 1a, ESR-T1: $11.8 \%$, ESR-T2: 17.0\%, and ESR-T3: 35.2\%, respectively). Specifically, the difference of incidence between ESR-T1 and ESR-T3 $(p<0.05)$, and between ESR-T2 and ESR-T3 $(\mathrm{p}<0.05)$, reached statistical significance. Similarly, by dividing patients into three subgroups based on the tertiles of hsCRP (hsCRP-T1: $\leq 2.3$ $\mathrm{mg} / \mathrm{L}$, hsCRP-T2: $2.3 \sim 4.5 \mathrm{mg} / \mathrm{L}$, and hsCRP-T3: $>4.5$ $\mathrm{mg} / \mathrm{L}$ ), we found that the occurrence of DKD rose when hsCRP elevated (Fig. 1b, hsCRP-T1: 15.8\%, hsCRP-T2: 23.6\%, and hsCRP-T3: 26.1\%, respectively). The difference of incidence between hsCRP-T1 and hsCRP-T2 $(p<0.05)$, and between hsCRP-T1 and hsCRP-T3 $(\mathrm{p}<0.05)$, reached significance.
Next, we examined the value of eGFR and ACR according to the tertiles of ESR or hsCRP. We found that from ESR-T1 to ESR-T2, and to ESR-T3, eGFR decreased from $95.74(85.17 \sim 104.37) \mathrm{ml} / \mathrm{min} / 1.73 \mathrm{~m}^{2}$ to $89.95(74.96 \sim 101.12) \mathrm{ml} / \mathrm{min} / 1.73 \mathrm{~m}^{2}$, and to 78.61 (54.09 94.77) $\mathrm{ml} / \mathrm{min} / 1.73 \mathrm{~m}^{2}$ (Fig. 2a), while ACR increased from $12.42(6.61 \sim 33.83) \mathrm{mg} / \mathrm{g}$ to 16.64 (7.68 $70.54) \mathrm{mg} / \mathrm{g}$, and to $44.08(12.42 \sim 275.32) \mathrm{mg} / \mathrm{g}$ (Fig. 2b). Similarly, from hsCRP-T1 to hsCRP-T2, and to hsCRP-T3, eGFR decreased from 91.94 (78.41 101.34) $\mathrm{ml} / \mathrm{min} / 1.73 \mathrm{~m}^{2}$ to $91.17 \quad(75.62 \sim 101.55) \quad \mathrm{ml} / \mathrm{min} /$ $1.73 \mathrm{~m}^{2}$, and to $84.49(58.48 \sim 98.92) \mathrm{ml} / \mathrm{min} / 1.73 \mathrm{~m}^{2}$ (Fig. 2c), while ACR increased from 12.61 (7.33 40.99) $\mathrm{mg} / \mathrm{g}$ to 18.61 (7.94 93.59) $\mathrm{mg} / \mathrm{g}$, and to 32.12 (11.80 $155.08) \mathrm{mg} / \mathrm{g}$ (Fig. 2d).

Given the different ESR normal range between male and female, gender-based subgroup analysis was conducted. Based on subgroup data, the tertiles for male were $\leq 7 \mathrm{~mm} / \mathrm{h} \quad(\mathrm{mT} 1), \quad 7 \sim 15 \mathrm{~mm} / \mathrm{h} \quad(\mathrm{mT} 2)$, and $>15$ $\mathrm{mm} / \mathrm{h}$ (mT3). Accordingly, eGFR decreased from 95.82 $(84.75 \sim 104.31)$ to 91.41 (78.85 100.92), and to 79.62 (57.82 94.56) (Fig. 3a), while ACR increased from
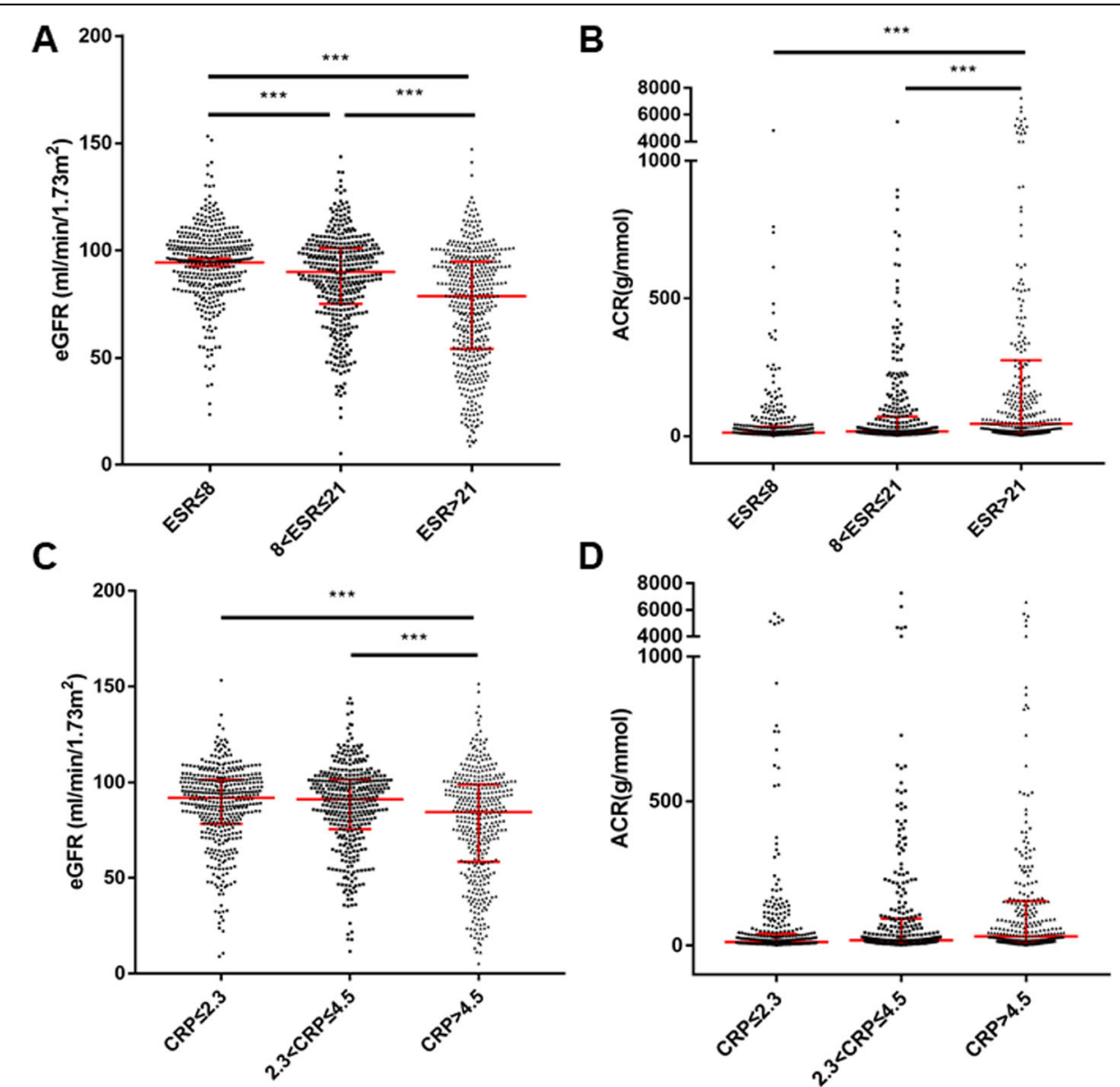

Fig. 2 eGFR and ACR according to ESR or CRP tertiles. Data was shown as median with interquartiles. ${ }^{* *}: p<0.001$. ESR: erythrocyte sedimentation rate, CRP: C reactive protein, eGFR: estimated glomerular filtration rate, ACR: albumin creatinine ratio 

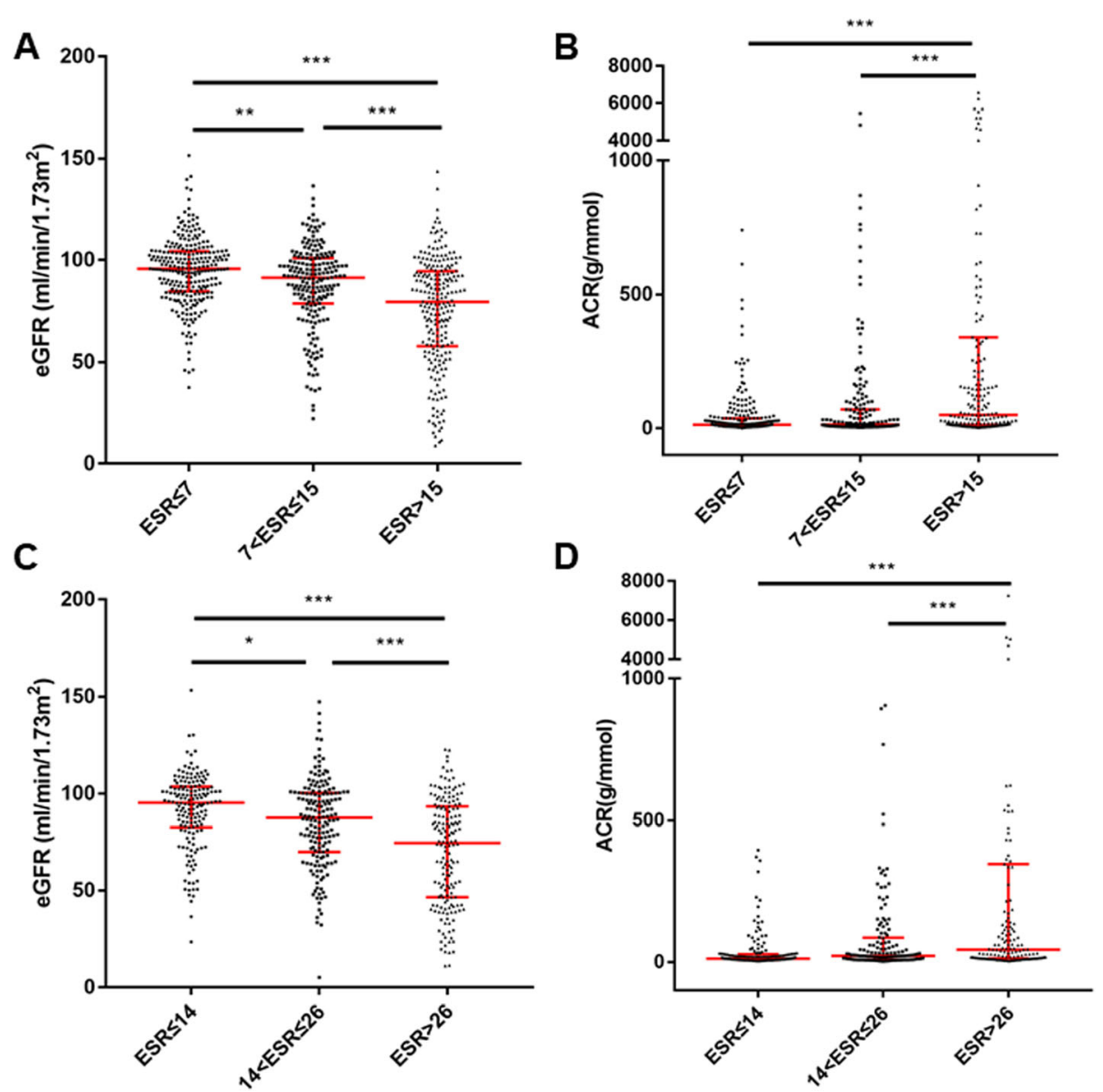

Fig. 3 eGFR and ACR according to ESR tertiles in female and male. Data was shown as median with interquartiles. ${ }^{*}: p<0.05,{ }^{* *}: p<0.01,{ }^{* * *}: P<0.001$. ESR: erythrocyte sedimentation rate, eGFR: estimated glomerular filtration rate, ACR: albumin creatinine ratio

$12.84(6.59 \sim 37.00)$ to $14.38(6.59 \sim 70.76)$, and to 49.56 $(12.29 \sim 340.07)$ (Fig. 3b).

For female, the tertiles were $\leq 14 \mathrm{~mm} / \mathrm{h}$ (fT1), $14 \sim 26$ $\mathrm{mm} / \mathrm{h}$ (fT2), and $>26 \mathrm{~mm} / \mathrm{h}$ (fT3). Accordingly, eGFR decreased from $95.24(82.57 \sim 103.50)$ to 87.59 (69.89 100.35) (Fig. 3c), and to 74.52 (46.51 93.40), while
ACR increased from $12.33(7.36 \sim 28.05)$ to 22.00 (8.41 $\sim 86.10$ ), and to 43.85 (13.35 345.77) (Fig. 3d).

ESR was independently associated with DKD in T2DM Logistic analysis showed that the risk of DKD increased with the upregulation of ESR, even after adjustment for

Table 2 Relationship between erythrocyte sedimentation rate or high-sensitivity C-reactive protein levels and diabetic kidney

\begin{tabular}{|c|c|c|c|c|c|}
\hline Variables & Group & $\begin{array}{l}\text { Model } 1 \text { OR } \\
(95 \% \mathrm{CI})\end{array}$ & $P$ value & $\begin{array}{l}\text { Model } 2 \text { OR } \\
(95 \% \mathrm{Cl})\end{array}$ & $P$ value \\
\hline \multirow[t]{3}{*}{$\overline{E S R}(\mathrm{~mm} / \mathrm{h})$} & $\mathrm{T} 1(<9)$ & reference & & reference & \\
\hline & T2 $(9 \sim 20)$ & $1.52(1.01 \sim 2.29)$ & 0.04 & $1.22(0.78 \sim 1.93)$ & 0.39 \\
\hline & T3 $(\geq 20)$ & $4.04(2.80 \sim 5.84)$ & $<0.001$ & $2.42(1.45 \sim 4.03)$ & $<0.001$ \\
\hline \multirow[t]{3}{*}{ hsCRP (mg/L) } & $\mathrm{T} 1(<2.2)$ & reference & & reference & \\
\hline & $\mathrm{T} 2(2.2 \sim 4.5)$ & $1.65(1.15 \sim 2.35)$ & 0.006 & $1.05(0.68 \sim 1.61)$ & 0.83 \\
\hline & $\mathrm{T} 3(\geq 4.5)$ & $1.89(1.34 \sim 2.67)$ & $<0.001$ & $1.40(0.95 \sim 2.08)$ & 0.09 \\
\hline
\end{tabular}

Model 1: unadjusted

Model 2: adjusted for age, gender, hypertension, hemoglobin, $\mathrm{TC}, \mathrm{HDL}, \mathrm{ALB}, \mathrm{GLB}, \mathrm{HbA}_{1 \mathrm{c}}$ and the usage of RAS inhibitor, metformin, and aspirin 
age, gender, hypertension, hemoglobin, TC, HDL, ALB, $\mathrm{GLB}, \mathrm{HbA}_{1 \mathrm{c}}$, and the usage of RAS inhibitor. However, hsCRP was not an independent risk factor for DKD after adjustment for confounders (Table 2). Furthermore, based on the adjusted model, ESR was significantly negatively related to eGFR and positively correlated to ACR (Table 3).

\section{Discussion}

In this study, we found that patients with DKD had higher ESR and hsCRP levels than those without DKD. Moreover, ESR but not hsCRP was independently related to the risk and severity of DKD, as indicated by both eGFR and ACR.

Growing evidences underline the critical role of inflammation in the progression of DKD. In the early stage of DKD, macrophages accumulate in kidney and produce cell adhesion molecules, chemokines, and proinflammatory cytokines $[15,16]$, which recruit more macrophages into kidney and exacerbate inflammatory injury [17].

Inflammatory parameters such as TNF- $\alpha$ have been reported to be correlated with renal function in T2DM [18-22], suggesting the predictive potential of inflammatory marker in this disorder [23]. Numerous factors have been found to be prognostic. For example, Hussain et al. found that galectin-3 and growth differentiation factor15 were inversely related to eGFR and could be used as a biomarker of renal function [24]. Bian et al. identified serum Activin $\mathrm{A}$ as an indicator for the treatment efficacy of DKD [25]. By reviewing the progression of DKD, Cao et al. summarized several microRNAs that could be used as biomarkers and therapeutic targets in DKD [26]. However, the measurement of these factors is expensive, which limits their clinical application. On the other hand, ESR and hsCRP can provide valuable information in terms of inflammatory status in a cheap and convenient manner [27]. They are influenced by various inflammatory factors, making them sensitive to inflammation [28]. In the present study, we found that ESR, instead of hsCRP, was independently associated with the incidence and severity of DKD, indicating the role of ESR for prognosticating DKD onset and progression.

ESR has been in use since 1921 as a test of inflammatory reaction for tuberculosis [27]. As an indicator of inflammation, ESR is widely used as a predictive

Table 3 Multivariate association of erythrocyte sedimentation rate and severity of diabetic kidney disease

\begin{tabular}{lllll}
\hline Clinical & & & & \\
\cline { 2 - 5 } parameters & $\mathrm{B}$ & $\mathrm{SE}$ & beta & $\mathrm{P}$ \\
\hline eGFR & -0.262 & 0.031 & -0.137 & $<.001$ \\
ACR & 6.040 & 1.486 & 0.155 & $<.001$ \\
\hline
\end{tabular}

biomarker in various chronic diseases, including antineutrophil cytoplasmic antibody-associated vasculitis [29] and systematic inflammatory response syndrome [30], and can be an independent prognostic factor for osteomyelitis recurrence in patients with T2DM [31]. However, the relationship between ESR and DKD has not been proposed. Based on our findings, ESR elevated significantly in the patients with DKD and is independently associated with DKD. According to our multivariate logistic analysis, patients with higher ESR level were more likely to have concomitant DKD than those with lower ESR. Furthermore, ESR was positively related to the severity of DKD, measured by both renal function and urinary albumin secretion, suggesting the correlation between inflammation and DKD progression. Above all, as a widely-applied and inexpensive measurement, ESR can be an ideal parameter for DKD occurrence and severity in patients with T2DM.

Despite of few literatures on ESR and DKD, the relationship between hsCRP and T2DM or DKD has been widely investigated. In a cross-sectional study including 64 patients with T2DM, hsCRP was significantly higher in those with micro-albuminuria compared to those with normo-albuminuria [32]. Another study reported that hsCRP rose significantly in patients with CKD than those without CKD [33]. However, whether CRP is an independent risk factor for DKD is still controversial. Navarro et al. found that hsCRP was independently associated with albuminuria in T2DM [34]. By contrast, in a study with 467 patients with diabetes and 1014 controls, hsCRP was not independently related to microalbuminuria [35]. Similarly, a research showed that hsCRP was not independently related to eGFR or urinary albumin secretion, after adjusted for CKD risk factors [33]. Based on our findings with a sample size of 1210, hsCRP was not independently associated with DKD after adjusted confounding factors, although the hsCRP value was significantly higher in patients with DKD than those without DKD.

The current outcomes should still be interpreted with caution. First, this is a cross-sectional study which might have introduced bias. Longitudinal studies are required to define whether ESR could predict the onset of DKD. Besides, ESR was only obtained from a single measurement, which might not be able to reflect a relation over time. However, after taking confounders into consideration, ESR are still associated with measures of DKD.

\section{Conclusion}

In conclusion, the current research underlined the role of inflammation in DKD. Our study found that, both ESR and hsCRP correlated with DKD in T2DM, of which ESR was an independent risk factor for DKD and positively associated with severity of DKD. 


\section{Abbreviations}

hsCRP: High-sensitivity C-reactive protein; ESR: Erythrocyte sedimentation rate; DKD: Diabetic kidney disease; T2DM: Type 2 diabetes mellitus; eGFR: Estimated-glomerular filtration rate; ACR: Albumin creatinine ratio; ESRD: End-stage renal disease; TNF-a: Tumor necrosis factor-a; IL8: Interleukin-8; MCP1: Monocyte chemo-attractant protein-1; FBG: Fasting plasma glucose; $\mathrm{HbA}_{1}$ : Glycated hemoglobin; ALB: Albumin; GLB: Globulin; TC: Total cholesterol; TG: Triglyceride; HDL: High-density lipoprotein cholesterol; LDL: Low-density lipoprotein cholesterol; SCr: Serum creatinine; RAS: Renin-angiotensin system; RASi: Renin-angiotensin system inhibitor; WBC: White blood cell; NEU: Neutrophil granulocyte; Hb: Hemoglobin; BMI: Body mass index; OR: Odds ratio; Cl: Confidence interval; T: Tertile; SE: Standard error

\section{Acknowledgements}

None.

\section{Authors' contributions}

SZG and MW analyzed the data and organized the article. YFY, YPY, FS, QL and $\mathrm{MH}$ author summarized the measurements included in the research. YML and JW were responsible for the statistical methodology. WG and ZYZ were the corresponding authors and designed the study together. FFZ summarized patients' medical history and proceed statistical analysis in the revision process. All authors read and approved the final manuscript.

\section{Funding}

This work was supported by National Natural Science Foundation of China (No.81970716 and No. 81800720), Cultivation Project of Clinical Research of Shanghai Hospital Development Center (SHDC12018X04), Funding from Huashan Hospital North Affiliated to Fudan University (HSBY2016004) and Shanghai general hospital integrated traditional Chinese and western medicine special project under Grant (ZHYY-ZXYJHZX-1-01).

National Natural Science Foundation of China (No.81970716 and No. 81800720) funded the test of hsCRP and other laboratory examination. Cultivation Project of Clinical Research of Shanghai Hospital Development Center (SHDC12018X04) and Funding from Huashan Hospital North Affiliated to Fudan University (HSBY2016004) provided subsidies for physicians collecting data.

Shanghai general hospital integrated traditional Chinese and western medicine special project under Grant (ZHYY-ZXYJHZX-1-01) provided subsidies for researchers analyzing data and writing the manuscript.

\section{Availability of data and materials}

The datasets used and/or analyzed during the current study are available from the corresponding author on reasonable request.

\section{Ethics approval and consent to participate}

The study was approved by the institutional review board in accordance with the ethical standards established by ethics committee of Huashan Hospital. Written informed consent was obtained from all participants.

\section{Consent for publication}

Not applicable.

\section{Competing interests}

The authors declare that they have no competing interests.

\section{Author details}

1Department of Endocrinology and Metabolism, Huashan Hospital, Fudan University, 12 Wulumuqi Road, Shanghai 200040, China. ${ }^{2}$ Department of Endocrinology, Shanghai Ninth People's Hospital, Shanghai Jiaotong University, Shanghai, China. ${ }^{3}$ Department of Endocrinology, Jing'an District Center Hospital of Shanghai, Fudan University, Shanghai, China.

Received: 24 March 2020 Accepted: 24 June 2020

Published online: 13 July 2020

\section{References}

1. Zheng Y, Ley SH, Hu FB. Global aetiology and epidemiology of type 2 diabetes mellitus and its complications. Nat Rev Endocrinol. 2018;14(2):8898.
2. Tuttle KR, Bakris GL, Bilous RW, Chiang JL, de Boer IH, Goldstein-Fuchs J, Hirsch IB, Kalantar-Zadeh K, Narva AS, Navaneethan SD, et al. Diabetic kidney disease: a report from an ADA consensus conference. Diabetes Care. 2014:37(10):2864-83.

3. Calder PC, Albers R, Antoine JM, Blum S, Bourdet-Sicard R, Ferns GA, Folkerts G, Friedmann PS, Frost GS, Guarner F, et al. Inflammatory disease processes and interactions with nutrition. Br J Nutr. 2009;101(Suppl 1):S1-45.

4. Park DJ, Choi SE, Xu H, Kang JH, Lee KE, Lee JS, Choi YD, Lee SS. Chronicity index, especially glomerular sclerosis, is the most powerful predictor of renal response following immunosuppressive treatment in patients with lupus nephritis. Int J Rheum Dis. 2018.

5. Tashiro K, Koyanagi I, Saitoh A, Shimizu A, Shike T, Ishiguro C, Koizumi M, Funabiki K, Horikoshi S, Shirato I, et al. Urinary levels of monocyte chemoattractant protein-1 (MCP-1) and interleukin-8 (IL-8), and renal injuries in patients with type 2 diabetic nephropathy. J Clin Lab Anal. 2002;16(1):1-4.

6. Niewczas MA, Ficociello LH, Johnson AC, Walker W, Rosolowsky ET, Roshan B, Warram JH, Krolewski AS. Serum concentrations of markers of TNFalpha and Fas-mediated pathways and renal function in nonproteinuric patients with type 1 diabetes. Clin J Am Soc Nephrol. 2009;4(1):62-70.

7. Gohda T, Niewczas MA, Ficociello LH, Walker WH, Skupien J, Rosetti F, Cullere $X$, Johnson AC, Crabtree G, Smiles AM, et al. Circulating TNF receptors 1 and 2 predict stage 3 CKD in type 1 diabetes. J Am Soc Nephrol. 2012;23(3):516-24.

8. Pichler R, Afkarian M, Dieter BP, Tuttle KR. Immunity and inflammation in diabetic kidney disease: translating mechanisms to biomarkers and treatment targets. Am J Physiol Renal Physiol. 2017;312(4):F716-31.

9. Brigden ML. Clinical utility of the erythrocyte sedimentation rate. Am Fam Physician. 1999;60(5):1443-50.

10. Mirsaeidi M, Omar HR, Ebrahimi G, Campos M. The association between ESR and CRP and systemic hypertension in Sarcoidosis. Int J Hypertens. 2016; 2016:2402515.

11. Wang C, Gong Z, Hu S, Zhang G. Metallothionein-1 is associated with osteoarthritis disease activity and suppresses proinflammatory cytokines production in synovial cells. Int Immunopharmacol. 2019;75:105815.

12. Ren H, Wu C, Shao Y, Liu S, Zhou Y, Wang Q. Correlation between serum miR-154-5p and urinary albumin excretion rates in patients with type 2 diabetes mellitus: a cross-sectional cohort study. Front Med. 2020.

13. Kdoqi. KDOQI Clinical Practice Guidelines and Clinical Practice Recommendations for Diabetes and Chronic Kidney Disease. Am J Kidney Dis. 2007:49(2 Suppl 2):S12-154.

14. Whelton PK, Carey RM, Aronow WS, Casey DE Jr, Collins KJ, Dennison Himmelfarb C, DePalma SM, Gidding S, Jamerson KA, Jones DW, et al. ACC/ AHA/AAPA/ABC/ACPM/AGS/APhA/ASH/ASPC/NMA/PCNA guideline for the prevention, detection, evaluation, and Management of High Blood Pressure in adults: a report of the American College of Cardiology/American Heart Association task force on clinical practice guidelines. J Am Coll Cardiol. 2017;2017.

15. Chow F, Ozols E, Nikolic-Paterson DJ, Atkins RC, Tesch GH. Macrophages in mouse type 2 diabetic nephropathy: correlation with diabetic state and progressive renal injury. Kidney Int. 2004;65(1):116-28.

16. Zeng C, Shi X, Zhang B, Liu H, Zhang L, Ding W, Zhao Y. The imbalance of Th17/Th1/Tregs in patients with type 2 diabetes: relationship with metabolic factors and complications. J Mol Med (Berl). 2012;90(2):175-86.

17. Chow FY, Nikolic-Paterson DJ, Ozols E, Atkins RC, Rollin BJ, Tesch GH. Monocyte chemoattractant protein-1 promotes the development of diabetic renal injury in streptozotocin-treated mice. Kidney Int. 2006;69(1): 73-80.

18. Afsar B. The relationship between neutrophil lymphocyte ratio with urinary protein and albumin excretion in newly diagnosed patients with type 2 diabetes. Am J Med Sci. 2014;347(3):217-20.

19. Azab B, Daoud J, Naeem FB, Nasr R, Ross J, Ghimire P, Siddiqui A, Azzi N, Rihana N, Abdallah M, et al. Neutrophil-to-lymphocyte ratio as a predictor of worsening renal function in diabetic patients (3-year follow-up study). Ren Fail. 2012;34(5):571-6.

20. Huang W, Huang J, Liu Q, Lin F, He Z, Zeng Z, He L. Neutrophil-lymphocyte ratio is a reliable predictive marker for early-stage diabetic nephropathy. Clin Endocrinol. 2015;82(2):229-33.

21. Elmarakby AA, Sullivan JC. Relationship between oxidative stress and inflammatory cytokines in diabetic nephropathy. Cardiovasc Ther. 2012; 30(1):49-59. 
22. Navarro JF, Mora C. Diabetes, inflammation, proinflammatory cytokines, and diabetic nephropathy. TheScientificWorldJournal. 2006;6:908-17.

23. Heo JM, Park JH, Kim JH, You SH, Kim JS, Ahn CM, Hong SJ, Shin KH, Lim DS. Comparison of inflammatory markers between diabetic and nondiabetic ST segment elevation myocardial infarction. J Cardiol. 2012;60(3):204-9.

24. Hussain S, Habib A, Hussain MS, Najmi AK. Potential biomarkers for early detection of diabetic kidney disease. Diabetes Res Clin Pract. 2020;161: 108082.

25. Bian X, Griffin TP, Zhu X, Islam MN, Conley SM, Eirin A, Tang H, O'Shea PM, Palmer AK, McCoy RG, et al. Senescence marker activin a is increased in human diabetic kidney disease: association with kidney function and potential implications for therapy. BMJ Open Diabetes Res Care. 2019;7(1): e000720.

26. Cao Q, Chen XM, Huang C, Pollock CA. MicroRNA as novel biomarkers and therapeutic targets in diabetic kidney disease: an update. FASEB Bioadv. 2019;1(6):375-88

27. Osei-Bimpong A, Meek JH, Lewis SM. ESR or CRP? A comparison of their clinical utility. Hematology. 2007;12(4):353-7.

28. Lapić I, Padoan A, Bozzato D, Plebani M. Erythrocyte Sedimentation Rate and C-Reactive Protein in Acute Inflammation. Am J Clin Pathol. 2020;153(1): $1-16$.

29. Liang $H$, Xin M, Zhao L, Wang L, Sun M, Wang J. Serum creatinine level and ESR values associated to clinical pathology types and prognosis of patients with renal injury caused by ANCA-associated vasculitis. Exp Ther Med. 2017; 14(6):6059-63.

30. Ganesan V, Brown RD, Jimenez JA, De S, Monga M. C-reactive protein and erythrocyte sedimentation rate predict systemic inflammatory response syndrome after percutaneous Nephrolithotomy. J Endourol. 2017;31(7):638-44.

31. Lin Z, Vasudevan A, Tambyah PA. Use of erythrocyte sedimentation rate and C-reactive protein to predict osteomyelitis recurrence. J Orthop Surg (Hong Kong). 2016;24(1):77-83.

32. Gomes MB, Nogueira VG. Acute-phase proteins and microalbuminuria among patients with type 2 diabetes. Diabetes Res Clin Pract. 2004;66(1):31-9.

33. Lee BT, Ahmed FA, Hamm LL, Teran FJ, Chen CS, Liu Y, Shah K, Rifai N, Batuman V, Simon EE, et al. Association of C-reactive protein, tumor necrosis factor-alpha, and interleukin-6 with chronic kidney disease. BMC Nephrol. 2015;16:77.

34. Navarro JF, Mora C, Maca M, Garca J. Inflammatory parameters are independently associated with urinary albumin in type 2 diabetes mellitus. Am J Kidney Dis. 2003;42(1):53-61.

35. Festa A, D'Agostino R, Howard G, Mykkanen L, Tracy RP, Haffner SM. Inflammation and microalbuminuria in nondiabetic and type 2 diabetic subjects: the insulin resistance atherosclerosis study. Kidney Int. 2000;58(4): 1703-10.

\section{Publisher's Note}

Springer Nature remains neutral with regard to jurisdictional claims in published maps and institutional affiliations.

Ready to submit your research? Choose BMC and benefit from:

- fast, convenient online submission

- thorough peer review by experienced researchers in your field

- rapid publication on acceptance

- support for research data, including large and complex data types

- gold Open Access which fosters wider collaboration and increased citations

- maximum visibility for your research: over $100 \mathrm{M}$ website views per year

At BMC, research is always in progress.

Learn more biomedcentral.com/submissions 